\title{
Stability Performance of the Mixture of Bentonite and Zeolite as Landfill Liner
}

\author{
Mochamad Arief Budihardjo $^{1, *}$, Fadel Iqbal Muhammad ${ }^{1}$, Alfian Rizky Rizaldianto ${ }^{1}$, Endro Sutrisno ${ }^{1}$ and Irawan Wisnu \\ Wardhana ${ }^{1}$ \\ ${ }^{1}$ Department of Environmental Engineering, Faculty of Engineering, Diponegoro University, Semarang - Indonesia
}

\begin{abstract}
In some areas, compacted clay liner is chosen as leachate barrier for solid waste landfill. Due to the typical shape of the landfill, the compacted clay liner will be rested both in flat and sloping ground. Since clay has characteristics of low shear strength, improvement of shear stability of compacted clay liner is required. One of the stability methods to increase the shear strength of clay is by adding another material which has higher shear stability. In this study, bentonite is used to represent clay liner while zeolite is utilized as stabilizer material. Four compositions of bentonite with $0 \%, 5 \%, 10 \%, 15 \%$ addition of zeolite were prepared to investigate the stability performance of the mixtures. The results indicate that the addition of zeolite into bentonite has increased the friction angle of the bentonite. However, the addition of zeolite seems to alter the hydraulic performance of bentonite. The highest permeability is demonstrated by the bentonite with $15 \%$ of zeolite. Whether the permeability increases, the hydraulic performance of all the mixtures are still met the maximum permeability allowed for landfill liner.
\end{abstract}

Keywords: Clay liner; stability; bentonite; zeolite.

\section{Introduction}

One of the most common methods of final solid waste treatment is landfilling. In the landfill, organic and nonorganic waste is managed [1]. Organic solid waste will decompose and produce leachate [2]. Leachate is also formed by the percolation of rainwater into landfills; dissolving and rinsing the waste materials, including organic materials which resulted from biological decomposition processes of organic solid waste. Leachate also has different compositions based on various factors [3, 4]. Generally, organic materials in the leachate are humic acid and organic materials while inorganic materials are natrium, copper, cadmium, manganese, ammonium, iron, and calcium [5].

In order to prevent any environmental pollution specifically soil and groundwater contamination, the leachate should not escape from the landfill. Therefore, to avoid any contamination to soil and groundwater, the landfill must be equipped with a semi-permeable liner that function as leachate barrier [6]. Material that often used as a liner is clay materials including bentonite. Bentonite has low permeability value which is suitable to be used as a leachate retaining layer [7].

However, like most other clays, bentonite has low shear stability. This is a challenge because in general, the typical landfill has a flat contour on the base and incline contour on the side [8]. Therefore, the shear stability of the liner material is important specifically when the liner is installed on the sloping area of the landfill. The lack of shear stability of the material has the potential to cause a collapse of the liner on the sloping area [9] specifically when the liner is saturated and receives a load from the garbage pile and heavy equipment such as garbage trucks and compactors.

One of the efforts to improve the shear strength of the compacted clay is to stabilize the clay material. Clay stabilization can be achieved by improving the properties of clay through the addition of other materials to increase the strength of the clay. Clay properties that can be improved by stabilization include volume stability, strength or carrying capacity, permeability, and conservation or durability [10]. Material that has the potential as a stabilizer to increase soil shear strength is zeolite.

Zeolite has been widely used in the field of construction as a stabilizing material for soil. Zeolite is a soil stabilization material used to improve soil conditions or unstable soil material or soft soil [11]. The addition of zeolite aims to increase density, the bond between particles in the soil, carrying capacity, compressive strength and shear strength of soil material to support the construction on top of it [12]. However, another factor that should be taken into account while focusing on shear strength improvement of liner material is the permeability of the mixtures.

The addition of zeolite to bentonite has the opportunity to increase the shear strength of bentonite [13], but the increase in shear strength also has the potential to increase the permeability of mixed materials [14]. In this study, bentonite with the addition of zeolite with various variations was tested. Increasing the value of shear strength and permeability values for each variation of the mixture are discussed.

* Corresponding author: m.budihardjo@.ft.undip.ac.id 


\section{Materials and Methods}

\subsection{Tested materials}

The main materials used in this study were bentonite and zeolite. The bentonite was supplied from a supplier in East Java Province, Indonesia, while the zeolite was obtained from a distributor in Central Java Province, Indonesia. The bentonite came in powder form while zeolite was in the granule. To facilitate the mixing process and acquire a homogeneous mixture, zeolite was crushed so that it passes no. $40(0.475 \mathrm{~mm})$ sieve. The specific gravity of bentonite and zeolite are 2.35 and 2.65 respectively. Four variations of the mixtures were prepared as shown in Table 1.

Table 1. Bentonite-Zeolite variation

\begin{tabular}{|c|c|}
\hline Sample & Variation \\
\hline S0 & Bentonite \\
\hline S5 & Bentonite + Zeolite $5 \%$ \\
\hline S10 & Bentonite + Zeolite $10 \%$ \\
\hline S15 & Bentonite + Zeolite $15 \%$ \\
\hline
\end{tabular}

Variation S0 is pure bentonite without any zeolite addition while S5, S10, and S15 contain bentonite with zeolite addition of $5 \%, 10 \%$ and $15 \%$ correspondingly. The determination of the percentage was performed by considering the research conducted in the previous study [15]. The samples of bentonite and zeolite in various percentages were made by mixing bentonite and zeolite in dry conditions. Once a homogeneous mixture was obtained, aquades was added in each mixture according to the $\mathrm{OMC}$ of each mixtures.

\subsection{Experimental setup}

The main test of this study was the testing of shear strength and permeability. Prior measurement of shear strength and permeability, a standard proctor test was carried out to determine optimum water content (OMC) and maximum dry density (MDD). Those experiments were needed to determine the mass and water content required for each variation for direct shear and permeability testing. In addition, the physical characteristic tests of the material were also carried out through atterberg limit test consisted of the liquid limit, plastic limit, and plasticity index.

The determination of OMC and MDD for each variation was carried out by referring to the Standard Proctor Test (ASTM D-698) [16] while the atterberg limit test was carried out in accordance with ASTM D4318 [17]. Shear strength testing was carried out by direct shear test according to ASTM D 3080-90 [18]. The direct shear test is intended to obtain cohesion value (C) and friction angle angles (Ø) of the mixtures. Meanwhile, the determination of the permeability for all mixtures was carried out by Falling Head Method in accordance with ASTM D5084-03 [19].

\section{Result and Discussion}

\subsection{Testing of Optimum Water Content (OMC) and Maximum Dry Density (MDD)}

Determination of Optimum Moisture Content (OMC) and Maximum Dry Density (MDD) from variations in bentonite and zeolite composites was carried out by the Standard Proctor test. The OMC and MDD values of each mixture are shown in Table 2.

Table 2. OMC and MDD of Bentonite-Zeolite mixture

\begin{tabular}{|c|c|c|}
\hline Sample & OMC (\%) & MDD $(\mathbf{g r} / \mathbf{c m 3})$ \\
\hline S0 & 45 & 1.088 \\
\hline S5 & 43.5 & 1.123 \\
\hline S10 & 41 & 1.192 \\
\hline S15 & 38 & 1.249 \\
\hline
\end{tabular}

Table 2 indicates that the OMC of S0, S5, S10 and S15 range from $45 \%$ to $38 \%$ while the MDD of all samples varies from $1.088 \mathrm{gr} / \mathrm{cm} 3$ to $1.249 \mathrm{gr} / \mathrm{cm} 3$. The moisture content of bentonite-zeolite mixtures tends to decrease along with the increasing of zeolite addition percentage. Meanwhile, the addition of zeolite increases the MDD of the mixtures. This result is consistent with the previous study by Kolay and Ramesh [16] who stated that the addition of stabilizer material reduces the water absorption capacity of the soil.

\subsection{Atterberg limit test}

Atterberg limit test has the purpose of determining the atterberg consistency to observe the water content in the state of plastic, liquid limit, and plastic index of the mixtures. The results of the atterberg limit test are shown in Table 3.

Table 3. Atterberg result of Bentonite-Zeolite mixture

\begin{tabular}{|c|c|c|c|}
\hline Sample & $\begin{array}{c}\text { Liquid } \\
\text { Limit (\%) }\end{array}$ & $\begin{array}{c}\text { Plastic Limit } \\
\text { (\%) }\end{array}$ & $\begin{array}{c}\text { Plasticity } \\
\text { Index (\%) }\end{array}$ \\
\hline S0 & 115.38 & 43.615 & 71.76 \\
\hline S5 & 110.25 & 47.763 & 63.87 \\
\hline S10 & 106.365 & 54.447 & 51.92 \\
\hline S15 & 100.57 & 54.916 & 45.65 \\
\hline
\end{tabular}

According to the results presented in Table 3, the addition of zeolite tends to increase the plastic limit and decrease the liquid limit and plasticity index. The addition of $0 \%, 5 \%, 10 \%$, and $15 \%$ of zeolite to the bentonite give plasticity index of $71.76 \%, 63.87 \%$, $51.92 \%$ and $45.65 \%$ respectively. The addition of zeolite tends to reduce the capacity of water retention of bentonite [11].

\subsection{Direct Shear Testing}

Direct shear testing aims to determine cohesion (c) and friction angle $(\varnothing)$ of the mixtures. Direct shear testing is carried out for all bentonite zeolite mixtures. The relationship between normal stress and shear stress used 
to determine $\mathrm{C}$ and $\varnothing$. The relationship between shear stress and normal stress presented in Fig. 1-4.

Fig. 1 depicts the relationship between normal stress and shear stress of S0. Three normal stresses of $50 \mathrm{kPa}$, $100 \mathrm{kPa}$ and $200 \mathrm{kPa}$ were applied to the sample of S0. The shear stress values obtained were respectively 33.83 $\mathrm{kPa}, 44.3 \mathrm{kPa}$, and $69.7 \mathrm{kPa}$. These results generate the cohesion value $(\mathrm{C})$ of 21.45 and the friction angle $(\varnothing)$ of $13.2^{\circ}$. This result is consistent with previous study by [12] who stated that zeolite may enhance soil stability.

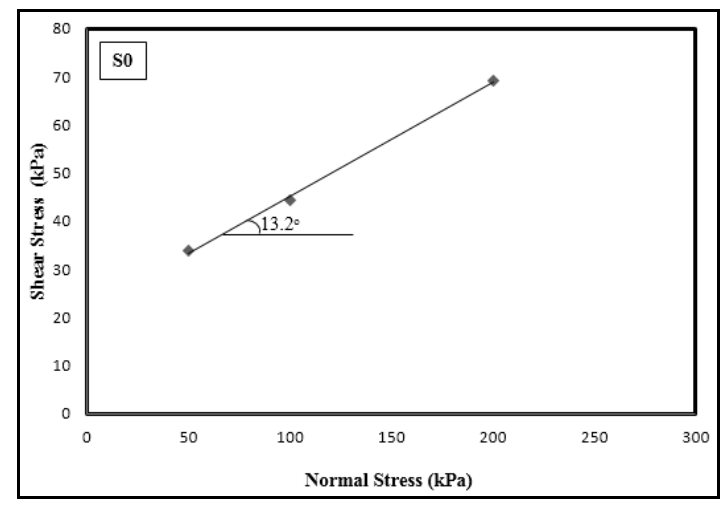

Fig. 1. Direct shear result of S0

Fig. 2 shows the result of direct shear testing of S5 loaded with three different normal stresses. The maximum shear stress at $50 \mathrm{kPa}$ is $35.73 \mathrm{kPa}$, while the highest shear stress of normal stress of $100 \mathrm{kPa}$ and 200 $\mathrm{kPa}$ are respectively $47.06 \mathrm{kPa}$ and $72.29 \mathrm{kPa}$. These results produce cohesion (C) value of 22.11 and the friction angle $(\varnothing)$ of $13.7^{\circ}$. The addition of zeolite seems to improve the shear stress and friction angle of the bentonite [12].

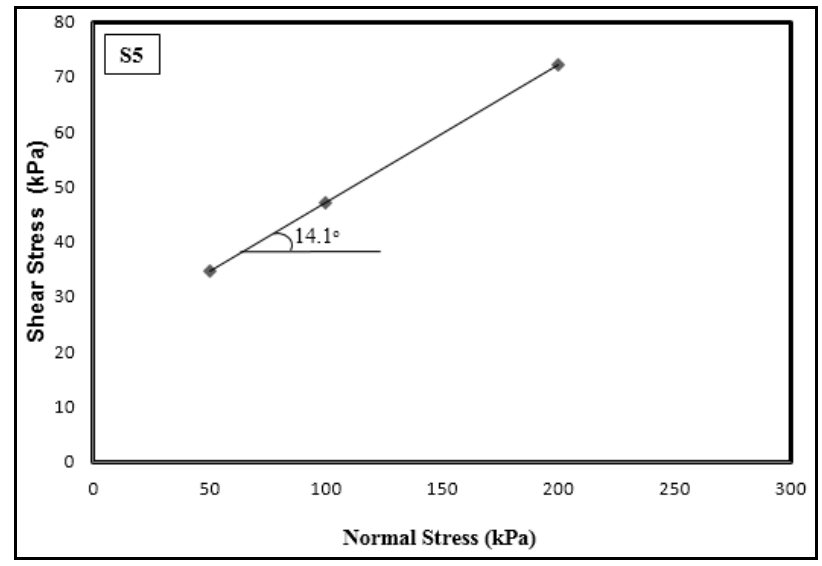

Fig. 2. Direct shear result of S5

The result of direct shear testing of sample S10 is illustrated in Figure 3. The sample S10 that consists of bentonite with $10 \%$ of zeolite was also subjected to three different normal stresses of $50 \mathrm{kPa}, 100 \mathrm{kPa}$, and 200 $\mathrm{kPa}$. The shear stresses generated by these loads are $36.26 \mathrm{kPa}, 51.83 \mathrm{kPa}$, and $79.45 \mathrm{kPa}$ correspondingly. This S10 mixture produces shear stress (C) of 22.45 and friction angle $(\varnothing)$ of $16.1 \mathrm{o}$. The stabilization of bentonite by addition of zeolite seems to improve the shear stress of the mixture [12].

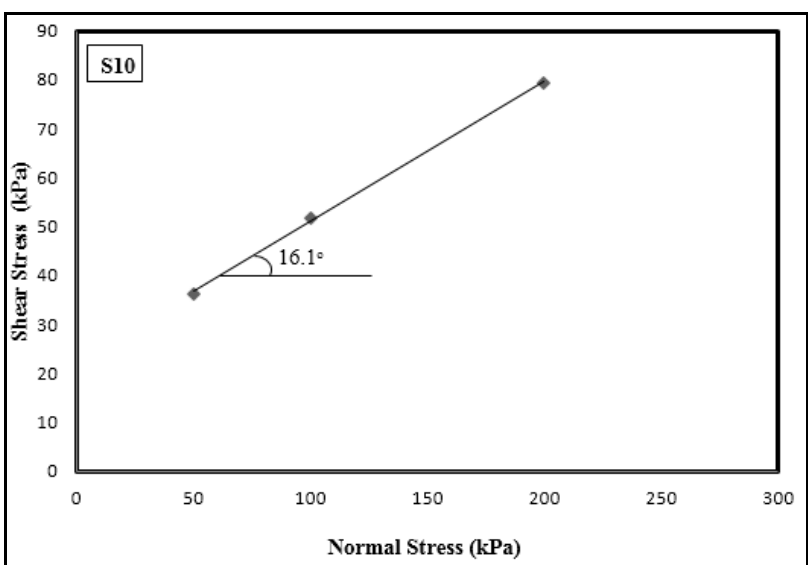

Fig. 3. Direct shear result of S10

Fig. 4 shows the result of shear strength test of bentonite mixed with $15 \%$ of zeolite. Consistent with other samples, the $\mathrm{S} 15$ also loaded with $50 \mathrm{kPa}, 100 \mathrm{kPa}$ and $200 \mathrm{kPa}$ of normal stresses. The shear stresses recorded for those three normal stresses are $37.33 \mathrm{kPa}$, $59.3 \mathrm{kPa}$, and $84.07 \mathrm{kPa}$. The relationship between normal stress and shear stress produces cohesion value (C) of 24.94 and a fiction angle (Ø) of $17.3^{\circ}$. The more zeolite added to the bentonite mixture appears to increase the stability of the bentonite [11].

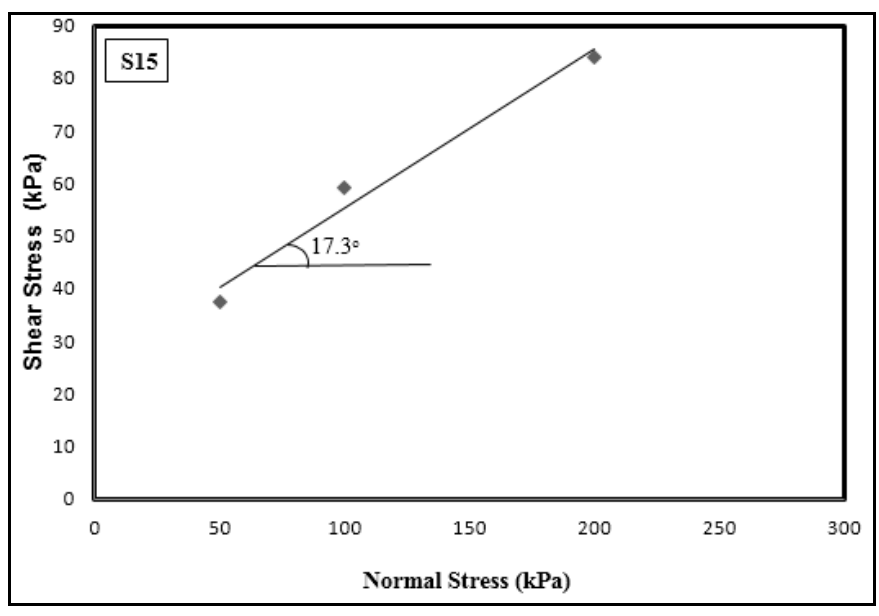

Fig. 4. Direct shear result of S15

\subsection{Permeability testing}

Landfill liner should not have a greater permeability value of $1 \times 10-9 \mathrm{~cm} / \mathrm{s}$ [21]. In order to examine whether any alteration on the hydraulic performance of zeolite induction to bentonite, falling head method was performed to measure the hydraulic conductivity of all mixtures. The results of the permeability testing are presented in Table 4.

Table 4. Result of Permeability testing

\begin{tabular}{|c|c|}
\hline Sample & Permeability (k) (cm/s) \\
\hline S0 & $1.3 \times 10^{-11}$ \\
\hline S5 & $4.2 \times 10^{-11}$ \\
\hline S10 & $5.6 \times 10^{-11}$ \\
\hline S15 & $9.3 \times 10^{-11}$ \\
\hline
\end{tabular}


The coefficient permeability of pure bentonite which is represented by sample $\mathrm{S} 0$ is $1.3 \times 10-11 \mathrm{~cm} / \mathrm{s}$. The addition of $5 \%$ zeolite results in an increment of hydraulic conductivity of the mixture to $4.2 \times 10-11$ $\mathrm{cm} / \mathrm{s}$. Bentonite containing $10 \%$ and $15 \%$ of zeolite produce higher permeability value of $5.6 \times 10-11 \mathrm{~cm} / \mathrm{s}$ and $9.3 \times 10-11 \mathrm{~cm} / \mathrm{s}$ respectively. It can be inferred that zeolite induction affects the hydraulic conductivity of the mixture to rise along with the percentage of the zeolite addition [11]. However, the highest permeability value of the mixture is still under the maximum value of hydraulic conductivity required for landfill liner. Therefore, all the mixtures are still acceptable to be utilized as leachate barrier in the landfill.

\section{Conclusion}

The typical shape of landfill requires liner to be installed whether in flat or sloping ground. Placing of a liner in the incline area demands a material with higher shear stability. Compacted clay as one of alternative material for liner has characteristic of low permeability and low shear strength. Therefore, to improve the stability of compacted clay, the induction of higher shear strength material to improve clay stability is needed. In this study, bentonite was selected as a landfill liner and mixed with zeolite which acted as a stabilizer. The experiment mainly focused on direct shear and permeability testing. Four different mixtures of bentonite containing different percentages of zeolite $(0 \%, 5 \%$, $10 \%$, and $15 \%$ ) were prepared to be tested. The results indicated that the higher the percentage of zeolite inducted into bentonite the higher friction angle was generated. Bentonite with $0 \%$ of zeolite has a friction angle of $13.2 \mathrm{o}$ while bentonite mixtures with $5 \%, 10 \%$, $15 \%$ addition of zeolite produce friction angle of $14.1 \mathrm{o}$, 16.10 , and 17.30 correspondingly. On the other hand, the improvement of shear stability by zeolite addition has compromised the permeability of the mixture. The addition of $5 \%, 10 \%$ and $15 \%$ of zeolite have increased the hydraulic conductivity to $4.2 \times 10-11 \mathrm{~cm} / \mathrm{sec}, 5.6 \mathrm{x}$ $10-11 \mathrm{~cm} / \mathrm{sec}$, and $9.3 \times 10-11 \mathrm{~cm} / \mathrm{sec}$. However, the permeability value of all mixtures is still met the maximum hydraulic conductivity required as a leachate barrier.

\section{References}

1 M.A. Budihardjo, J. Solid Waste Technol. Manag. 44, 206-213 (2018)

2 L. Behrooznia, M. Sharifi, R. Alimardani, S.H. Mousavi-Avval, J. Clean. Prod. 203, 1028-1038 (2018)

3 A.B. Mochamad, H. Mochtar, H. Haryono Setiyo, A.F. Rahma, E3S Web Conf. 73, 07017 (2018)

4 A.M. Costa, R.G.de.S.M. Alfaia, J.C. Campos, J. Environ. Manage. 232, 10-116 (2019)

5 M.A. Budihardjo, Purwono, A.S. Nugraheni, MATEC Web Conf. 159, 02031 (2018)

6 S. Shu, W. Zhu, S.W. Wang, C.W.W. Ng, Y. Chen, A.C. Fai Chiu, Sci. Total Environ. 612, 1123-1131
(2017)

7 B. Li, L. Y. Li, J.R. Grace, J. Environ. Manage. 156, 236-243 (2015).

8 S.-J. Feng, Z.-W. Chen, H.-X. Chen, Q.-T. Zheng, R. Liu, Eng. Geol. 241, 76-85 (2018).

9 Y. Gao, Y. Yin, B. Li, K. He, X. Wang, Waste Manag. 83, 171-183 (2019)

10 S.-J. Feng, K.-W. Gao, Y.-X. Chen, Y. Li, L. M. Zhang, H. X. Chen, Waste Manag. 63, 354-365 (2017)

11 Y. Yukselen-Aksoy, Appl. Clay Sci. 50, 130-136 (2010)

12 M. Turkoz, P. Vural, Sci. Eng. Compos. Mater. 20 (2013)

13 A. Tuncan, M. Tuncan, H. Koyuncu, Y. Guney, Waste Manag. Res. 21, 54-61 (2003)

14 H. Xu, W. Zhu, X. Qian, S. Wang, X. Fan, Appl. Clay Sci. 132-133, 326-335 (2016)

15 A.H. Ören, A. Kaya, A.Ş. Kayalar, Can. Geotech. J. 48, 1343-1353 (2011).

16 ASTM D698-00a, Annu. B. ASTM Stand. (2000)

17 ASTM D4318, ASTM Int. 14 (2005)

18 ASTM D3080-90, ASTM Stand. (1994)

19 ASTM D5084-03, Annu. B. ASTM Stand., (2003)

20 P.K. Kolay, K.C. Ramesh, Geotech. Geol. Eng. 34, 87-101 (2016)

21. Y.J. Du, R.D. Fan, S.Y. Liu, K.R. Reddy, F. Jin, Eng. Geol. 195, 258-268 (2015) 